\title{
Localização das aglomerações do setor industrial nas regiões Nordeste e Sudeste: uma análise comparativa nos governos FHC e Lula
}

\section{Industrial sector's agglomerations locations in the industrial sector in the Northeast and Southeast regions: a comparative analysis in the FHC and Lula governments}

\author{
William Eufrásio Nunes Pereira ${ }^{1}$ \\ Ana Cristina dos Santos Morais ${ }^{2}$ \\ Francisco Danilo da Silva Ferreira ${ }^{3}$ \\ Severino Félix de Souza ${ }^{4}$
}

\section{RESUMO}

O presente artigo tem por objetivo verificar as alterações no padrão locacional do setor industrial no Sudeste e Nordeste do País, durante os governos Fernando Henrique Cardoso (FHC) e Luiz Inácio Lula da Silva (Lula), com a utilização do coeficiente locacional de Hoover. Para a operacionalização do índice, foi utilizado o emprego formal no setor industrial nos anos de 1995, 2002, 2003 e 2010, correspondentes respectivamente aos anos iniciais e finais dos governos FHC e Lula. Os resultados alcançados revelam que houve perdas na indústria no Governo FHC, assim como, a hegemonia na concentração do emprego industrial no Sudeste foi reduzida relativamente nos anos seguintes do seu Governo. No governo Lula, a região Nordeste perdeu empregos.

Palavras-chave: Índice do Hoover; Emprego formal, Indústria, Nordeste, Sudeste.

\begin{abstract}
This paper aims to verify the industrial locational pattern changes in the Southeast and Northeast of the country, during the Fernando Henrique Cardoso (FHC) and Luiz Inácio Lula da Silva (Lula), using the locational coefficient Hoover. The operationalization of the index, we used formal employment in the industrial sector in 1995, 2002, 2003 and 2010, corresponding respectively to the initial and final years of $\mathrm{FHC}$ and Lula. The results showed losses in the industry during the Cardoso government, as well as leadership in the industrial employment and concentration in the Southeast, in conclusion, the region's importance declined in the following years of his government. During Lula's government, the Northeast region lost employments.
\end{abstract}

Keywords: Hoover's Index; Formal employment, Industry, Northeast, Southeast.

JEL: R12, L16, R30.

\footnotetext{
1 Professor DEPEC/Universidade Federal do Rio Grande do Norte (UFRN) E-mail : wenpereira2014@gmail.com

2 Pós-Doutoranda em Economia (UFRN). Doutora em Economia (UFPA). Mestre em Economia

(UFRN). Graduada em Ciências Econômicas (UFRN). E-mail : crystynamorays@gmail.com

${ }^{3}$ Professor Assistente do Departamento de Economia da Universidade Estadual do Rio Grande do Norte. E-mail : ffdanilloferreira@gmail.com

${ }^{4}$ Doutorando em Economia pelo Programa de Pós-Graduação em Economia na Universidade Federal do Pará - UFPA. E-mail : severinofelix@hotmail.com
} 


\section{INTRODUÇÃO}

As diversas teorias da localização industrial (Von Thünen, Weber, Perroux, Lösch, Christaller, dentre outros) apontaram inúmeros fatores que determinariam a localização de uma indústria, dentre os quais temos: a dotação de fatores, as economias de escala e as economias externas (PEREIRA, 2008).

No Brasil, o padrão de distribuição geográfica das atividades industriais seguiu o padrão mundial. Inicialmente, ocorreu uma forte concentração da atividade industrial na região Sudeste do país, sobretudo no estado de São Paulo, para em um segundo momento ocorrer uma redistribuição de algumas atividades, em direção às áreas consideradas periféricas. Essa redistribuição (que não deve ser entendida com desconcentração) foi possível em função de políticas econômicas engendradas no intuito de diminuir as desigualdades regionais. Essas políticas caracterizavam-se, principalmente, pelo aumento no investimento em setores econômicos importantes para geração de emprego e renda nas unidades da federação fora do contexto Sudeste/Sul (CANO, 2007).

No entanto, é preciso destacar que as inversões realizadas nas áreas periféricas possuíam aspectos complementares à indústria do Sudeste e, mais especificamente, a indústria paulista. Os benefícios das alocações dos investimentos se concentraram nas áreas mais dinâmicas das regiões. No caso da região Nordeste esses investimentos foram alocados, em especial, nos estados da Bahia, Pernambuco e Ceará. A política de desconcentração foi desenvolvida até finais da década de 1970, contribuindo para a desconcentração produtiva até meados da década de 1980 (CAIADO, 2002), como também, prolongando o crescimento econômico, mesmo em um período de crise (CANO, 2007), sendo estes dois fenômenos, frutos do amadurecimento dos investimentos do II Plano Nacional de Desenvolvimento - II PND.

Entretanto, as duas crises do petróleo (1973 e 1979) exerceram implicações perversas sobre os países subdesenvolvidos, dentre estes o Brasil. De acordo com Cano (2007, p. 10) "o efeito imediato foi o corte substancial do financiamento externo", se desdobrando no agravamento dos indicadores macroeconômicos. Diante disto, o Estado brasileiro passa a apresentar limitações financeiras, inviabilizando a realização dos investimentos públicos. Cano (2007, p.11) mostra que "essa conjunção fez com que diminuísse a ação do estado no plano nacional e regional. Além disso, debilitou o investimento privado", esvaziando assim, o estado brasileiro ocorrendo, segundo Caiado (2002, p.113), uma "desarticulação dos mecanismos de apoio ao desenvolvimento regional".

A década de 1980, considerada por muitos como a década perdida, devido a grande crise socioeconômica vivida pelo país, está vinculada diretamente ao processo de endividamento externo, que serviu como elemento impulsionador do desenvolvimento econômico brasileiro na década de 1970. A origem da crise capitalista brasileira, na década de 1980, encontra-se na década anterior e na crise do capital. Com a exigência dos países desenvolvidos do pagamento dos juros pelos países do terceiro mundo, fez com que o Brasil reduzisse a taxa de investimento, no intuito de alocar recursos para o pagamento da dívida. 
William Eufrásio Nunes Pereira, Ana Cristina dos Santos Morais, Francisco Danilo da Silva Ferreira, Severino Felix de Souza

A redução deu-se em várias áreas, principalmente, em infraestrutura, energia, saúde e educação, ocasionando uma forte recessão decorrente da necessidade de pagamento da dívida. A tentativa de solucionar o problema partia da busca por ampliar as exportações e reduzir o grau das importações, visando arrecadar recursos para o pagamento da dívida externa, que se agravava, em virtude da instalação de um processo hiperinflacionário que, em conjunto com a hiperinflação, expandia-se assustadoramente através de uma espiral de preços, salário e juros, acelerada pela forte indexação existente na economia brasileira.

Os anos 1990 foram marcados pela ruptura com o paradigma nacionaldesenvolvimentista das décadas anteriores. As políticas de desenvolvimento regional e de redução das disparidades regionais esvaecem da agenda do estado brasileiro haja vista que adotara o receituário neoliberal, o qual preza pela ideia do estado mínimo. Diante disto, a falta de políticas nacionais de desenvolvimento regional conduzido pelo governo central, induziu às unidades subnacionais, em especial as unidades da federação, a executarem políticas de isenção fiscal e financeira, suscitando uma disputa por investimentos privados, principalmente, os industriais (VARSANO, 1997).

As políticas estaduais de desenvolvimento industrial ficaram resumidas à guerra fiscal entre as unidades da Federação, travada mediante a concessão de incentivos fiscais e financeiros, normalmente relacionados ao ICMS. As renúncias fiscais, vistas como "investimentos", por parte dos concedentes, deterioraram as condições financeiras, já fragilizadas pelo endividamento, dos estados e municípios.

Essa guerra fiscal consiste em uma situação de conflito na federação, na qual os únicos a ganharem são os empresários e, relativamente, os estados mais estruturados financeiramente (VARSANO, 1997). Historicamente, a concessão de incentivos fiscais-financeiros atraiu para alguns estados empreendimentos produtivos, e se constituíram no principal fator de atratividade, sem poder de sustentação na localidade ao fim do incentivo (OLIVEIRA, 1990).

Alguns mecanismos fiscais e parafiscais, com raras exceções, não foram utilizados pelas unidades federativas. Estados, como a Bahia e a Paraíba, utilizaram quase todos os tipos de incentivos relacionados ao ICMS, simultaneamente. Outros tipos de benefícios não relacionados ao ICMS também foram utilizados, destacandose os estímulos para infraestrutura (venda de lotes e galpões, locação de máquinas e equipamentos, doação de áreas), as concessões financeiras (aquisição de ativos fixos, composição acionária, entre outros.) e, ainda, incentivos como a simplificação do processo de registro de empresas, a assistência técnica na elaboração de projetos e os programas de formação e capacitação.

Alguns estados deram ênfase às questões tecnológicas na concessão dos incentivos, destacando-se a Bahia, Goiás, Minas Gerais, o Paraná, o Rio de Janeiro e São Paulo. Notadamente, nesse grupo, encontram-se os estados com as maiores economias da federação. Os diversos incentivos fiscais e parafiscais em conjunto com a abundância de determinados fatores produtivos, a exemplo mão de obra barata, e, não sindicalizada, contribuíram para relocalização de determinados empreendimentos industriais, em particular, os intensivos em mão de obra.

O presente artigo tem por objetivo verificar possíveis alterações no padrão locacional do setor industrial do Sudeste e Nordeste do País, durante os governos FHC e Lula. Para tanto, será empregado o coeficiente locacional de Hoover e o emprego formal como variável de análise.

Após os aspectos introdutórios, ressalta-se que o estudo se encontra dividido em mais quatro itens. No primeiro, encontra-se a apresentação dos principais 
fundamentos teóricos do artigo. Na sequência é apresentado procedimentos metodológicos e a base de dados da pesquisa. Posteriormente, analisam-se os resultados obtidos. Por fim, na última seção, apresenta-se algumas considerações finais.

\section{FUNDAMENTAÇÃO TEÓRICA ACERCA DA QUESTÃO EM ESTUDO}

Ao longo da década de 1990, houve transformações significativas na localização da indústria nacional, lembrando que esta desconcentração ocorria em direção a alguns estados do Norte, Nordeste e Centro-Oeste. O processo do desenvolvimento econômico do Brasil pode ser entendido através de um modelo no qual as riquezas estão concentradas em atividades produtivas organizadas, especialmente, no Sudeste do Brasil, processo esse que faz com que as demais regiões desfrutem de um desnível acentuado. Portanto, o processo de industrialização tardia e concentrador estariam entre os vários fatores responsáveis por este cenário (SABOIA, 2000; ABEL, NUNES, 2009).

A desconcentração industrial é um processo que, segundo Pacheco (1999), tende a ter certa continuidade em direção ao interior de São Paulo e aos principais estados do Sul e do Sudeste, desconcentrando até mesmo para o Nordeste, no caso das indústrias que necessitam de um grande volume de mão de obra. A afirmação é corroborada por Azevedo e Toneto Júnior (2001), ao afirmarem que a tendência desconcentradora observada no período 1974/88 estaria se acentuando, na década de 1990. Ainda segundo os autores, os setores com abundância em trabalho migraram para regiões que ofereciam baixos salários.

Para Sabóia (2013), existe a confirmação de que o processo desconcentrador, em especial, o processo da indústria brasileira, continuou de forma bastante clara e intensa nos anos 2000, beneficiando, principalmente, a região Sul do Brasil. Porém, houve um esvaziamento na indústria alocada na Região Metropolitana de São Paulo e em outras Regiões Metropolitanas do Sul/Sudeste.

Conforme Diniz e Campolina (2007), a importância dos serviços modernos, como a tecnologia e os investimentos, ampliou seus mercados, o que compensou a queda da participação na produção industrial. As evidências da desconcentração industrial mostram que ela acontece de forma mais intensiva no segmento de recursos naturais e de forma contrária, mais suave no intensivo capital (SILVA, SILVEIRA NETO, 2009).

$\mathrm{Na}$ história econômica, a desconcentração industrial foi vista de diversas formas. Segundo Caiado (2002) muitos dos efeitos da desconcentração produtiva dava-se proveniente de efeitos de políticas de incentivo ao desenvolvimento regional. Este desenvolvimento promovia investimento em indústrias e expandia a fronteira agrícola e ainda a grandes projetos como exemplo das hidrelétricas, siderúrgicas, químicos, entre outros. Este tipo de desconcentração era tido como um movimento desconcentrador de forma virtuosa onde através de grandes investimentos, 0 crescimento econômico e a desconcentração produtiva eram notáveis.

No Brasil, verificou-se um desenvolvimento fora das aglomerações no período entre 1978 a 1998. Esse desenvolvimento gerou diversas alterações nas maiores aglomerações econômicas do país, como por exemplo, Rio de Janeiro, que perderia o posto de "capital política e econômica" para São Paulo (DOMINGUES, RUIZ, 2006).

Guimarães Neto (1989 p. 131) têm sua tese centrada "no entendimento de que a rentabilidade proporcionada pelos subsídios ao capital desempenhou um papel decisivo no aumento do investimento no Nordeste". Esse pensamento corrobora com 
William Eufrásio Nunes Pereira, Ana Cristina dos Santos Morais, Francisco Danilo da Silva Ferreira, Severino Felix de Souza

Caiado (2002), em que o movimento desconcentrador era ocorria de forma espúria, tendo como objetivo ampliar para manter a competitividade. Este processo era realizado através da redução de custos via redução de salários com redução das cargas tributárias e muitas vezes por subsídios realizados pelos governos estaduais.

Nesse contexto, a região Sudeste, em especial São Paulo, ainda é o centro dinâmico do capital e dos investimentos. Para Silva e Neto (2009) apesar de todo esse movimento de desconcentração, o emprego formal da indústria de transformação contínua concentrado nas regiões Sul e Sudeste.

Para Lautert e Araújo (2007), em linhas gerais, grupos que dispõem de maior conteúdo tecnológico em especial produtores de bens intermediários e de capital estariam com uma concentração maior, em contrapartida, os grupos que fazem parte da indústria tradicional - que correspondem em geral, os produtores de bens de consumo não duráveis - se apresentavam com um índice menor de concentração.

Dessa forma, para Cano $(1998 ; 2007)$ embora tenha ocorrido um movimento de desconcentração, no entanto, o motor da economia continuava sendo o estado de São Paulo e a região Sudeste, pois esta abarcava a maioria dos investimentos, portanto, a concentração ainda é a realidade existente. Essa inflexão dava-se devido a diversos fatores, tais como: as políticas desenvolvimentistas no cenário regional; debilidade fiscal e financeira dos governos estaduais e federal; localização em São Paulo dos principais investimentos em tecnologia, automação, bem como os demais itens da cadeia produtiva.

Baseado em todo esse arcabouço empírico, segundo Resende e Wyllie (2005), tornou-se notória a heterogeneidade entre as regiões. Heterogeneidade que exsurgese como um dos fatores responsável por influir nos processos de concentração e desconcentração industrial do país. Sem esquecer também, como afirma Hirschman (1961), que alguns países possuem o êxito inicial no progresso e na concentração industrial, devido à sorte ou fatores ambientais, que muitas vezes são esquecidos e substituídos pelas suas maneiras de agir em relação às qualidades morais superiores.

As regiões Sul e Sudeste foram aquelas que mais sofreram com os efeitos negativos no mercado de trabalho, em função de processos já mencionados (reestruturação produtiva, abertura comercial, entre outros.) pelos quais passava a economia brasileira na década de 1990. Além disso, ocorreu uma mudança locacional de alguns segmentos do setor industrial beneficiando alguns estados, porém, acabou prejudicando outros, em que o autor cita como exemplo a indústria calçadista do Ceará (GUIMARÃES NETO, 1989; MORAIS, 2015).

No início dessa mesma década, o Plano Collor I, não só promoveu a abertura comercial, como também, criou um conjunto de medidas denominadas "Diretrizes Gerais para a Política Industrial e de Comércio Exterior - (PICE)" (SILVA, 2008, p. 118). Esse conjunto de medidas concomitante à abertura da economia aprofundou $a$ crise brasileira, visto que a indústria brasileira não tinha como concorrer com os produtos favorecidos pela redução das tarifas de importações (MORAIS, 2015).

De acordo com Silva (2008), no início do governo Fernando Henrique Cardoso, o processo de reestruturação produtiva alcançou maior velocidade, dado às políticas liberais que promoveram, no período de 1994 a 1998, "a estabilização monetária, a abertura comercial e a reforma do Estado", promovendo "uma breve retomada do crescimento econômico no Brasil” (SILVA, 2008, p. 119).

Por fim, como explica Abel e Nunes (2009), esse movimento de concentração e desconcentração muitas vezes sofre influência das políticas públicas, em especial as políticas fiscais, que ficaram conhecidas como "guerra fiscal". Desta forma, "através 
dessa política, o processo de (re)localização espacial da indústria, proporcionado por políticas de reestruturação produtiva, garantiria a promoção do desenvolvimento nacional com mais equidade e equilíbrio" (ABEL, NUNES, 2009, p. 317).

\section{METODOLOGIA E BASE DE DADOS}

A presente seção tem por escopo descrever os procedimentos metodológicos a serem empregados no presente trabalho, com o intuito de atingir o objetivo almejado e especificado na introdução. Para tanto, faz-se necessário apresentar alguns aspectos importantes relacionados ao tratamento dos dados, assim como, do quociente locacional de Hoover.

Ressalte-se que os dados do emprego formal do setor industrial no estudo em tela, foram coletados no Relatório Anual de Informações Sociais, nos seguintes subsetores que compõem a indústria : O extrativo mineral; o mineral não metálicos; o metalúrgico; o mecânico; o elétrico e de comunicações; o de material de transportes; o de madeira e mobiliário; o de papel e gráfico; o de borracha, fumo e couros; 0 químico; o têxtil; o calçadista; o de alimentos e bebidas; o de serviços de utilidade pública; e, o da construção civil. Estes quinze subsetores industriais compõem o setor da indústria, conforme categorização do IBGE.

\section{O QUOCIENTE LOCACIONAL DE HOOVER}

O presente trabalho apresenta como estratégica metodológica o emprego do quociente de localização (QL), com a finalidade de avaliar possíveis alterações no padrão locacional das regiões Sudeste e Nordeste durante os anos de 1995 a 2010. Neste sentido, para a execução do QL foram empregados dados de origem secundária, correspondentes ao emprego formal na indústria na região Sudeste e Nordeste, para os anos de 1995, 2002, 2003 e 2010, o qual corresponde aos anos iniciais e finais dos governos FHC e Lula. Os referidos dados são procedentes da Relação Anual de Informações Sociais (RAIS) os quais podem ser obtidos junto ao site do Ministério do Trabalho. Especificamente, utilizou-se os vínculos ou empregos formais dos quinze subsetores industriais definidos pelo IBGE. Trata-se de números agregados nos quinze subsetores, mas que para o objetivo desse trabalho se adéqua satisfatoriamente.

O QL mostra o comportamento dos segmentos do setor industrial, bem como a atividade mais especializada, em determinado espaço. Para visualizar a especialização da indústria no Brasil, faz-se necessário utilizar o índice de localização, definido a partir do quociente de localização (HOOVER, 1936), o qual é dado a partir da seguinte equação:

$$
\mathrm{QL}=\frac{\frac{E_{\mathrm{ij}}}{E_{j}}}{\frac{E_{\mathrm{iBR}}}{E_{\mathrm{BR}}}}
$$

onde $E_{\mathrm{ij}}$ é o emprego da atividade da indústria $i$ na região j, $E_{j}$ é o emprego industrial total na região j, $E_{\mathrm{iBR}}$ é o emprego da atividade industrial $i$ no Brasil, e $E_{\mathrm{BR}}$ é o emprego industrial total no Brasil. Ressalte-se que os resultados estão demonstrados integralmente nos anexos deste trabalho. 
William Eufrásio Nunes Pereira, Ana Cristina dos Santos Morais, Francisco Danilo da Silva Ferreira, Severino Felix de Souza

Quanto aos resultados desse indicador, nas atividades em que o valor numérico for menor ou igual a 1 (um), a atividade econômica da cidade não possui especialização no segmento. Contudo, se o valor for superior a 1 (um), provavelmente, seja um segmento com uma possível especialização do emprego, pois está acima da média da região de referência. Ressalta-se que quanto maior for o resultado do $Q L$ mais especializada estará a cidade $j$ no setor $i$ da economia.

O QL pode apresentar algumas "distorções" quando analisado isoladamente, em função de sua limitação metodológica. Isso ocorre dada a heterogeneidade da estrutura produtiva das regiões brasileira, em que, algumas cidades têm uma única indústria concentrando a maior quantidade de empregos gerados no setor.

Vários estudos têm sido realizados com a utilização do índice de localização (ou quociente de localização) da indústria no intuito de auxiliar na identificação de aglomerações das atividades econômicas. Nesse sentido, Soares et al., (2008) analisam o impacto da especialização do setor industrial a nível de microrregiões, a partir da utilização do quociente locacional. Os resultados mostraram que as microrregiões com $Q L$ acima de 2 possuíam um significativo impacto sobre a escala de produção.

Paiva (2006) afirma que há uma ambiguidade quanto ao termo especialização, pois se há especialização de uma determinada atividade, deveria existir também sua ampliação. "Especializar-se é conquistar competências específicas, o que significa conquistar novos patamares de domínio do geral com vistas à consecução de fins específicos" (PAIVA, 2006, p. 90). O autor mostra ainda a importância do índice de localização para a comparação do setor produtivo de uma determinada região em relação à macrorregião onde está localizado.

Rezende, Campolina e Paixão (2012) destacam a localização da indústria de transformação no Brasil, visando identificar a distribuição das atividades produtivas brasileiras. Para tanto, os autores utilizam o índice como um indicador de concentração dos segmentos do setor industrial. De acordo com os autores, no período entre 1994 a 2009, verifica-se uma desconcentração da indústria brasileira, porém, esse fenômeno não ocorreu de forma igualitária pelo território nacional, visto que cada espaço tem seu próprio ritmo e dinâmica capaz de atrair determinadas atividades. Outros autores (RAIHER, FERRERA e STADUTO, 2006) também utilizaram o índice de especialização em estudos econômicos que versam sobre 0 desenvolvimento regional.

Nas diversas tabelas contidas no anexo, pode-se observar os dados absolutos e relativos que permitem novos trabalhos e novas interpretações consoantes ou dissonantes com o trabalho em tela.

\section{ANÁLISE DOS DADOS E RESULTADOS OBTIDOS}

O emprego na indústria brasileira em 1995 era, hegemonicamente, concentrado no Sudeste, que empregava mais de $60 \%$ de todos os vínculos formais do setor. O Sul e Sudeste, ainda, são as regiões com maior quantidade de empregos formais no Brasil.

Contudo, ocorreu uma mudança espacial das atividades produtivas. Verificase que essa redistribuição do emprego industrial para as demais regiões, visto que no caso do Sudeste cerca de $10 \%$ da produção se relocalizou em outros espaços do Brasil. Embora seja uma pequena redistribuição do ponto de vista relativo, quando observados os dados absolutos, o Nordeste passou de 787.131 em 1995 para 
1.736.302 empregos formais em 2010, apenas no setor industrial. Portanto, do ponto de vista absoluto, foi um processo de redistribuição que beneficiou trabalhadores com carteira de trabalho assinada não apenas no Nordeste, mas estendeu-se para as demais regiões.

Nesse contexto, há uma responsabilidade dos municípios - fazendo referência aos seus gestores - no que se refere ao papel de inserção das cidades no cenário econômico brasileiro, possibilitado mais pela sua situação geográfica, em que essas cidades estão inseridas dentro de uma determinada região, do que pelo seu tamanho demográfico. A Tabela 1 mostra a participação do emprego industrial nas regiões do Brasil.

Tabela 1 - Participação do emprego formal nas regiões do Brasil - 1995, 2002, 2013 e 2010.

\begin{tabular}{ccc|c|c|c}
\hline Anos & Norte & Nordeste & Sudeste & Sul & $\begin{array}{c}\text { Centro- } \\
\text { Oeste }\end{array}$ \\
\hline $\mathbf{1 9 9 5}$ & 2.88 & 12.18 & 60.30 & 20.82 & 3.81 \\
$\mathbf{2 0 0 2}$ & 3.60 & 13.96 & 53.30 & 24.00 & 5.14 \\
$\mathbf{2 0 0 3}$ & 3.67 & 13.73 & 53.04 & 24.33 & 5.23 \\
$\mathbf{2 0 1 0}$ & 4.32 & 15.77 & 51.73 & 22.26 & 5.92 \\
\hline
\end{tabular}

Fonte: Elaboração com base nos dados da RAIS/MTE.

De acordo com a Tabela 1, essa hegemonia na concentração do emprego industrial na região Sudeste reduziu-se nos governos de FHC e Lula. Nessa região, ao final do ano de 1995, encontrava-se mais de 3,8 milhões de pessoas empregadas no setor. E, em 2010, contava com, aproximadamente, 5,7 milhões de empregos no setor. Simultaneamente ao crescimento absoluto no volume de vínculos, ocorreu um declínio relativo na participação do número dos postos de trabalho no Sudeste. Do ponto de vista relativo, o Norte foi à região que apresentou maior crescimento no período, isso ocorreu, em parte, pelas políticas de incentivo que beneficiaram alguns estados daquela região. No caso da região Sul, em 2010, detinha aproximadamente $22 \%$ do emprego industrial brasileiro. Portanto, verifica-se que, em 1995, 81\% dos empregos na indústria estavam concentrados nas regiões Sudeste e Sul. Porém, em 2010 esse percentual reduziu-se para 74\%.

O Gráfico 1 mostra a taxa de crescimento do emprego industrial por região no Brasil nos respectivos governos. Comparando os períodos em análise, constata-se que o período $2003 / 2010$ se constituiu, do ponto de vista do emprego formal industrial, em um período com o maior crescimento dessa variável para todas as regiões brasileiras. Ao observar o período 2003/2010, a taxa de crescimento do emprego foi bastante significativa ao comparar com o período anterior. Portanto, ocorreu uma recuperação no emprego formal na indústria brasileira, desencadeando um processo de crescimento nas quantidades de postos de trabalhos formais em direção para outras regiões fora do contexto SUL. 
William Eufrásio Nunes Pereira, Ana Cristina dos Santos Morais, Francisco Danilo da Silva Ferreira, Severino Felix de Souza

Gráfico 1 - Crescimento do emprego formal na indústria, no Brasil: 2000/1990 e 2010/2000 (\%).

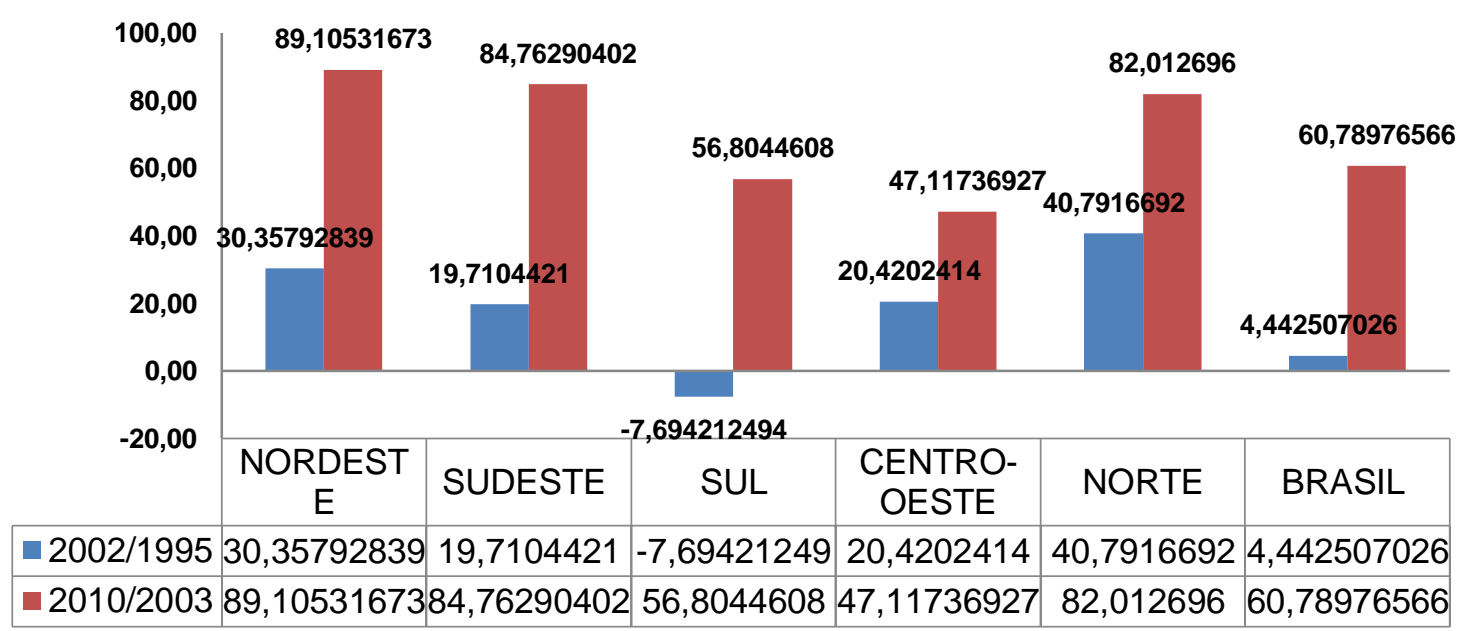

Fonte: Elaboração com base nos dados da RAIS/MTE.

Entre 2002 e 2003, o aumento na quantidade emprego formal no período ficou aquém do desejado, principalmente para a região Sul que apresentou queda na quantidade de vínculo de aproximadamente sete pontos percentuais. Nos anos 2003 a 2010, esse aumento se deu de forma significativa. No Brasil, o setor industrial aumentou em mais de 4,5 milhões de empregos, sendo que, apenas no Sudeste foram mais de 2,0 milhões de novos postos de trabalho. Esse dado demonstra que as políticas públicas implementadas pelo governo Lula em consonância com 0 crescimento econômico mundial que puxou as exportações brasileiras, tiveram importância significativa na ampliação dos vínculos formais industriais, os quais foram superiores ao período do Governo FHC.

Verifica-se que o Sudeste continuou perdendo participação relativa no total do emprego industrial. Em 2002, o Sudeste respondia por 53,3\% e em 2010 apenas $51,7 \%$ dos vínculos formais na indústria. No segundo período o incremento na indústria do Sudeste foi de mais de 56,8\% e no Brasil mais de 60,7\%. O diferencial explica a perda relativa do Sudeste frente ao restante do Brasil. Vale ressaltar, que em 2010 são cinco os subsetores industriais do Sudeste que detém menos de 50\% dos vínculos formais totais do País. Acresceram-se os subsetores têxteis, de vestuário e artefatos de tecido e o da construção civil. As diversas explicações qualitativas para as perdas do Sudeste. Destacam-se as questões da terceirização, quarteirização, inserção tecnológica, etc. Mas esse debate foge aos limites deste trabalho, e essas questões também atingem ademais regiões, mesmo que em intensidade diferente (quadros em anexo).

Situação inversamente ocorre com o Nordeste. Em 1995, a região respondia por $12,2 \%$ dos vínculos formais industriais do País. Nenhum dos subsetores apresentava um quarto ou mais de vínculos totais. O subsetor mais empregador era a tradicional indústria de produtos alimentícios, bebidas e álcool etílico. Poucas foram as mudanças no período $\mathrm{FHC}$. A participação relativa da região nos vínculos formais totais da indústria aumentou de $12,2 \%$ para $13,9 \%$. A grande mudança foi a participação na indústria calçadista que de $7 \%$ aumentou para mais de $22 \%$. Esse 
subsetor, intensivo em mão de obra, foi o que mais cresceu devido, principalmente, a relocalização dos empreendimentos do Sudeste para o Nordeste.

Em 2010, o subsetor calçadista nordestino já era responsável por um, em cada três vínculos formais no total do emprego no segmento brasileiro. A participação total da indústria nordestina alcança $15,8 \%$ dos vínculos formais totais da indústria brasileira. Dos subsetores industriais apenas o extrativo mineral e o de produtos alimentícios, bebidas e álcool apresentaram declínio relativo em suas participações no quantum nacional. Os demais 13 subsetores apresentaram crescimento.

\section{Resultados do Quociente de Localização (QL)}

A Tabela 2 mostra a quantidade de clusters e sua evolução no Nordeste para os anos 1995, 2002, 2003 e 2010. Em 1995 os segmentos com maiores aglomerações na Região eram a construção civil, com a Bahia liderando com 42.736 empregos formais, e os serviços industriais de utilidade pública, com um total de 8 cada um. Alagoas foi o único estado que apresentou índice inferior a 1.

Tabela 2 - Evolução da quantidade de aglomeração econômica segundo os subsetores da indústria no Nordeste - 1995, 2002, 2003 e 2010.

\begin{tabular}{l|c|c|c|c|c|c|c|c|}
\hline \multirow{2}{*}{ SUBSETORES } & \multicolumn{7}{c|}{ NORDESTE } \\
\cline { 2 - 9 } & $\mathbf{1 9 9 5}$ & $\mathbf{2 0 0 2}$ & Saldo & $\begin{array}{c}\text { Evolução } \\
\%\end{array}$ & $\mathbf{2 0 0 3}$ & $\mathbf{2 0 1 0}$ & Saldo & $\begin{array}{c}\text { Evolução } \\
\%\end{array}$ \\
\hline EXTR MINERAL & 5 & 4 & -1 & $-20,0$ & 5 & 3 & -2 & $-40,0$ \\
MIN NAO MET & 7 & 7 & 0 & 0,0 & 7 & 7 & 0 & 0,0 \\
IND METALURG & 1 & 1 & 0 & 0,0 & 1 & 0 & -1 & $-100,0$ \\
IND MECANICA & 0 & 0 & 0 & 0,0 & 0 & 0 & 0 & 0,0 \\
ELET E COMUM & 0 & 0 & 0 & 0,0 & 0 & 0 & 0 & 0,0 \\
MAT TRANSP & 0 & 0 & 0 & 0,0 & 0 & 0 & 0 & 0,0 \\
MAD E MOBIL & 1 & 1 & 0 & 0,0 & 1 & 0 & -1 & $-100,0$ \\
PAPEL E GRAF & 0 & 1 & 1 & 0,0 & 0 & 0 & 0 & 0,0 \\
BOR FUM COUR & 1 & 0 & -1 & $-100,0$ & 1 & 0 & -1 & $-100,0$ \\
IND QUIMICA & 1 & 1 & 0 & 0,0 & 1 & 1 & 0 & 0,0 \\
IND TEXTIL & 5 & 5 & 0 & 0,0 & 5 & 3 & -2 & $-40,0$ \\
IND CALCADOS & 2 & 3 & 1 & 50,0 & 3 & 4 & 1 & 33,3 \\
ALIM E BEB & 7 & 7 & 0 & 0,0 & 7 & 2 & -5 & $-71,4$ \\
SER UTIL PUB & 8 & 6 & -2 & $-25,0$ & 7 & 7 & 0 & 0,0 \\
CONSTR CIVIL & 8 & 7 & -1 & $-12,5$ & 7 & 7 & 0 & 0,0 \\
\hline TOTAL NE & $\mathbf{4 6}$ & $\mathbf{4 3}$ & $-\mathbf{3}$ & $-6,5$ & $\mathbf{4 5}$ & $\mathbf{3 4}$ & $\mathbf{- 1 1}$ & $\mathbf{- 2 4 , 4}$ \\
\hline
\end{tabular}

Fonte: Elaboração com base nos dados da RAIS/MTE.

A indústria de alimentos só não apresenta representatividade no Maranhão e no Piauí. Quanto à extração mineral o estado com maior representatividade é o Rio Grande do Norte. Em 2002 a perda ocorreu no estado do Ceará, em termos absolutos foram mais de 300 empregos diretos, provocando uma redução da participação relativa no estado.

Quanto aos saldos, 2002 em relação a 1995, em números absolutos as maiores perdas ocorreram nos estados mais ricos da região. Pernambuco perdeu 22,3 mil empregos, Bahia 8,5 mil, nesses estados a maior perda de postos de trabalho ocorreu na indústria de alimentos. No Ceará a quantidade de empregos que deixaram de existir foi de 3,7 mil apenas na construção civil. 
William Eufrásio Nunes Pereira, Ana Cristina dos Santos Morais, Francisco Danilo da Silva Ferreira, Severino Felix de Souza

No que se refere à evolução em alguns segmentos permanecerem inalterados ou com evolução negativa, percebe-se que apenas o Pernambuco teve a sua participação absoluta reduzida e foi o estado que mais sofreu perdas de postos de trabalho. No total de perdas para a Região foi de aproximadamente 50,4 mil empregos apenas no setor industrial. Tais reduções ocorreram em todos os estados do Nordeste e em 13 dos 15 segmentos da indústria, ou seja, os segmentos que não apresentaram perdas foram a indústria de produtos minerais não metálicos e a indústria metalúrgica.

Quanto ao período de 2003 a 2010 a redução no saldo não significa efetivamente que ocorreram perdas absolutas. Pois as perdas foram apenas $799 \mathrm{em}$ todo o Nordeste, nos estados do Maranhão 311 (indústria da madeira e do mobiliário), Paraíba na indústria do material elétrico (99) e no material de transporte (3), em Alagoas as perdas se concentraram na indústria da borracha (164) e na indústria têxtil (222). Isso mostra que o emprego no setor industrial do Nordeste no período 2003 a 2010 foi redistribuído nos demais segmentos do setor em todos os estados nordestinos.

A Tabela 3 mostra a quantidade de aglomerações econômicas e sua evolução no Sudeste para o período de 1995 a 2010. No período de 1995 a 2002 os segmentos com maiores aglomerações na Região eram a Indústria metalúrgica e a indústria têxtil, com maior concentração relativa no estado de Minas gerais. Diferente do Nordeste, a Região Sudeste apresenta aglomerações em todos os segmentos do setor e com 12 segmentos com saldo zero, enquanto no Nordeste esse quantitativo era de 9. Nesse período a perda de empregos no setor foi num total de 403.465 pessoas desempregadas.

Tabela 3 - Evolução da Aglomeração econômica segundo os subsetores da indústria no Sudeste 1992-2010.

\begin{tabular}{l|r|r|r|rrr|r|r}
\hline \multirow{2}{*}{ SUBSETORES } & \multicolumn{10}{c}{ SUDESTE } \\
\cline { 2 - 9 } & $\mathbf{1 9 9 5}$ & $\mathbf{2 0 0 2}$ & Saldo & $\begin{array}{r}\text { Evolução } \\
\text { \% }\end{array}$ & $\mathbf{2 0 0 3}$ & $\mathbf{2 0 1 0}$ & Saldo & $\begin{array}{c}\text { Evolução } \\
\%\end{array}$ \\
\hline EXTR MINERAL & 2 & 3 & 1 & 50,0 & 3 & 2 & -1 & $-33,3$ \\
MIN NAO MET & 2 & 2 & 0 & 0,0 & 2 & 2 & 0 & 0,0 \\
IND METALURG & 4 & 3 & -1 & $-25,0$ & 3 & 4 & 1 & 33,3 \\
IND MECANICA & 2 & 2 & 0 & 0,0 & 2 & 2 & 0 & 0,0 \\
ELET E COMUM & 2 & 2 & 0 & 0,0 & 2 & 2 & 0 & 0,0 \\
MAT TRANSP & 2 & 2 & 0 & 0,0 & 2 & 2 & 0 & 0,0 \\
MAD E MOBIL & 1 & 1 & 0 & 0,0 & 1 & 1 & 0 & 0,0 \\
PAPEL E GRAF & 3 & 3 & 0 & 0,0 & 3 & 3 & 0 & 0,0 \\
BOR FUM COUR & 2 & 2 & 0 & 0,0 & 2 & 2 & 0 & 0,0 \\
IND QUIMICA & 3 & 3 & 0 & 0,0 & 3 & 3 & 0 & 0,0 \\
IND TEXTIL & 4 & 2 & -2 & $-50,0$ & 2 & 4 & 2 & 100,0 \\
IND CALCADOS & 1 & 1 & 0 & 0,0 & 1 & 1 & 0 & 0,0 \\
ALIM E BEB & 1 & 1 & 0 & 0,0 & 1 & 1 & 0 & 0,0 \\
SER UTIL PUB & 3 & 3 & 0 & 0,0 & 3 & 3 & 0 & 0,0 \\
CONSTR CIVIL & 3 & 3 & 0 & 0,0 & 3 & 3 & 0 & 0,0 \\
INDÚSSTRIA SE & 35 & 33 & -2 & $-5,7$ & 33 & 35 & 2 & 6,1 \\
\hline
\end{tabular}

Fonte: Elaboração com base nos dados da RAIS/MTE.

No período de 2003 a 2010, diferente do período anterior, apenas duas atividades apresentam redução na quantidade absoluta de empregos, a extração 
mineral no Espírito Santo e a indústria de material elétrico e de comunicação no Rio de Janeiro. Nos demais segmentos do Sudeste o crescimento absoluto foi significativo. Para o Nordeste o crescimento pode ser visto ao comparar os Quadros 08 e 10, os quais mostram que ocorreu uma diversidade da produção no final do período em análise. Nessa redistribuição das atividades os ganhos foram maiores que as perdas, pois, dos 9 estados da Região as reduções de empregos foram pequenas.

A descentralização produtiva como face da reestruturação produtiva que se caracterizou por ser mais uma relocalização industrial do que uma descentralização de capitais. Isso se deve ao fato de a descentralização do principal centro produtor brasileiro ter ocorrido, em grande parte, dentro do próprio território, ou seja, as indústrias realocaram algumas plantas para cidades do interior, próximas à capital ou à região metropolitana de São Paulo.

O Nordeste pouco ganhou com esse processo de relocalização industrial no período de governo FHC. O ganho foi concentrado nos principais estados da região, além de vincular-se muito mais a setores tradicionais e intensivos em trabalho, em particular a indústria calçadista (PEREIRA, 2008). Mas isso tem sido uma constatação não apenas no Brasil, afinal Leborgne e Lipietz (1994) já avisavam que nem todas as regiões ganham em países que se beneficiam da relocalização, e algumas regiões ganham nos países que perdem. Nesse contexto, afirmam ainda que as regiões que tendem a ganhar são regiões urbanas, no caso do Nordeste, as beneficiadas foram as cidades médias e as que estavam próximas às regiões metropolitanas.

É necessário lembrar que os ganhos são essencialmente em empregos, empresas e produção. Outros ganhos existem, mas são limitados principalmente pelas perdas impostas ao município, ao Estado, ao meio ambiente, à fiscalidade e ao país em geral. As perdas relacionam-se às externalidades negativas, às deseconomias de aglomeração, como, por exemplo, à poluição, à renúncia fiscal, ao aumento dos preços, e às pressões sobre a infraestrutura. Em geral, o Nordeste beneficiou-se muito mais com a desconcentração industrial, ocorrida nos anos 1970 e 1985, do que a desconcentração recente (CANO, 2007).

\section{CONSIDERAÇÕES FINAIS}

No período compreendido entre 1995 e 2002, o emprego formal nas duas regiões obteve redução em quase todos os segmentos do setor industrial. No caso do Governo Lula, as perdas foram ínfimas quando comparadas ao Governo anterior. Ocorreu uma diversificação da produção entre os estados do Nordeste.

Quanto ao período de 2003 a 2010, a redução no saldo não significa efetivamente que ocorreram perdas absolutas. Pois as perdas foram apenas $799 \mathrm{em}$ todo o Nordeste, nos estados do Maranhão 311 (indústria da madeira e do mobiliário), Paraíba na indústria do material elétrico (99) e no material de transporte (3), em Alagoas as perdas se concentraram na indústria da borracha (164) e na indústria têxtil (222). Isso mostra que o emprego no setor industrial do Nordeste no período 2003 a 2010 foi redistribuído nos demais segmentos do setor em todos os estados nordestinos.

A Tabela 3 mostra a quantidade de aglomerações econômicas e sua evolução no Sudeste para o período de 1995 a 2010. No período de 1995 a 2002 os segmentos com maiores aglomerações na Região eram a Indústria metalúrgica e a indústria têxtil, 
William Eufrásio Nunes Pereira, Ana Cristina dos Santos Morais, Francisco Danilo da Silva Ferreira, Severino Felix de Souza

com maior concentração relativa no estado de Minas gerais. Diferente do Nordeste, a Região Sudeste apresenta aglomerações em todos os segmentos do setor e com 12 segmentos com saldo zero, enquanto no Nordeste esse quantitativo era de 9. Nesse período a perda de empregos no setor foi num total de 403.465 pessoas desempregadas.

No período de 2003 a 2010, diferente do período anterior apenas duas atividades apresentam redução na quantidade de empregos, a extração mineral no Espírito Santo e a indústria de material elétrico e de comunicação no Rio de Janeiro. Nos demais segmentos do Sudeste o crescimento absoluto foi significativo.

A principal contribuição do trabalho em tela, consiste em mostrar o "status" do processo de localização e relocalização recente da indústria nas regiões Sudeste e Nordeste. Constatar as diferenças abruptas existentes entre as duas regiões converge para a necessidade de novos trabalhos, estudos e pesquisas que aprofundem a questão, possibilitando a elaboração de subsídios para formatação e implantação de políticas que minimize as disparidades existentes no setor industrial nas regiões. Um maior equilíbrio distributivo pode atenuar inúmeros problemas econômicos e sociais, favorecendo a estabilidade federativa em suas diversas dimensões.

Novas pesquisas e trabalhos acadêmicos permitiram continuar a análise e observar que o crescimento dos vínculos formais na indústria se mantém ou não. Permitiram também estabelecer o ritmo do crescimento, determinando o nível de importância que tem o emprego industrial dentro do emprego total, sinalizando a importância da indústria dentro da economia brasileira. Por fim, esses novos estudos podem indicar que políticas econômicas adotadas nos dois períodos foram mais adequadas na geração de emprego industrial, permitindo assim, uma revisão nas políticas econômicas atuais.

\section{REFERÊNCIAS}

ABEL da S. F., L., NUNES. de Q., S. Políticas de concentração ou desconcentração industrial no território cearense? Administração Pública e Gestão Social, v1, n4, pp. 315-336, out/dez. 2009. Disponível em: <https://periodicos.ufv.br/apgs/article/view/4014>. Acesso em: 17 de janeiro. 2019.

AZEVEDO, P. F., TONETO JÚNIOR, R. Relocalização do emprego industrial formal no Brasil na década de 90. Pesquisa e Planejamento Econômico, v. 31, n. 1, pp. 153-186, abr. 2001. Disponível em: $<<$ http://repositorio.ipea.gov.br/bitstream/11058/5067/1/PPE v31 n01 Relocalizacao.p df $>>$ acesso em 20 de janeiro de 2019.

BRITO, A. F., BONELLI, R. Políticas industriais descentralizadas: as experiências europeias e as iniciativas subnacionais no Brasil. In. Planejamento e Políticas Públicas. V. 01, n. 01, pp. 163-215, Brasília, jun. de 1997. Disponível em: << https://www.ipea.gov.br/ppp/index.php/PPP/article/view/121/123 >> Acesso em $30 \mathrm{de}$ janeiro de 2019

CAIADO, A. S. C. Desconcentração Industrial Regional no Brasil (1985 - 1998): Pausa ou Retrocesso? Tese de Doutorado: Universidade Estadual de Campinas: 2002. 
CANO, W. Desequilíbrios Regionais e Concentração Industrial no Brasil (19301995) Campinas, IE/UNICAMP, 1998

CANO, W. Desconcentração Produtiva Regional do Brasil 1970-2005. São Paulo: UNESP, 2007.

DINIZ, C. C., CAMPOLINA, B. A Região Metropolitana de São Paulo:

Reestruturação, reespacialização e novas funções. Revista Eure, v. 33, n. 98, pp.

27-43, 2007. Disponível em:<<

https://scielo.conicyt.cl/scielo.php?script=sci arttext\&pid=S0250-

$\underline{71612007000100002 \& \operatorname{lng}=e s \& n r m=i s o}>>$ acesso em 10 de fevereiro de 2019

DOMINGUES, E. P. RUIZ, R. M. Aglomerações industriais e tecnológicas: origem do capital, inovação e localização. Economia e Sociedade, Campinas, v. 15, n. 3 (28), p. 515-543, dez. 2006.

FONSECA, P. C. D., CUNHA, A. M., BICHARA, J. da S. O Brasil na Era Lula: retorno ao desenvolvimento? Nova economia. Belo Horizonte, v. 23, n. 2, p. 403-

428, Aug. 2013. Available from

$<$ http://www.scielo.br/scielo.php?script=sci_arttext\&pid=S0103-

$63512013000200006 \&$ Ing $=$ en\&nrm $=$ iso $>$. access

on 27 Oct. 2020. https://doi.org/10.1590/S0103-63512013000200006.

GUIMARÃES NETO, L. Introdução à Formação Econômica do Nordeste. Recife: FUNDAJ; Editora Massangana, 1989.

HIRSCHMAN, Albert. A Estratégia de Desenvolvimento Econômico. Rio de Janeiro: Fundo de Cultura, 1961.

HOOVER, E. M. The measurement of industriallocalization. Review of Economic and Statistics, n. XVIII, p.162-171, 1936

LAUTERT, V. ARAUJO, N. C. M. de. Concentração industrial no Brasil no período 1996-2001: uma análise por meio do índice de Ellison e Glaeser (1994). Econ. Apl. [online]. 2007, vol.11, n.3, pp. 347-368. Disponível em : <<

http://www.revistas.usp.br/ecoa/article/view/955 >> disponível em 10 de janeiro de 2019.

LIPIETZ, Alain. Flexibilidad ofensiva, flexibilidad defensiva. Dos estrategias socialies en la producción de los nuevos espacios económicos. In: BENKO, G. e LIPIETZ, A. Las Regiones que Ganan, València: Alfons el Magnànim, pp.322-358, 1994.

LERBORGNE, D. LIPIETZ, A. Flexibilidad ofensiva, flexibilidad defensiva. Dos estrategias socialies en la producción de los nuevos espacios económicos. In: BENKO, G. e LIPIETZ, A. Las Regiones que Ganan, València: Alfons el Magnànim, pp. 357-386. 1994.

MORAIS, A. C dos. S. Cidades Médias não metropolitanas das Regiões Nordeste e Sudeste do Brasil: dinâmica do emprego industrial no período de 1990 a 2013. Dissertação de Mestrado - Centro de Ciências Sociais Aplicadas. CCSA. UFRN, Natal, 2015 
William Eufrásio Nunes Pereira, Ana Cristina dos Santos Morais, Francisco Danilo da Silva Ferreira, Severino Felix de Souza

OLIVEIRA, F de. A metamorfose da arribaçã: fundo público e regulação autoritária na expansão econômica do Nordeste. Novos Estudos Cebrap, São Paulo, n. 27, p. 67-92, jul.1990.

PACHECO, C. A. Novos padrões de localização industrial? Tendências recentes dos indicadores da produção e do investimento industrial. Texto para Discussão, n. 633. IPEA, Brasília, mar. 1999.

PAIVA, C. A. N. Desenvolvimento regional, especialização e suas medidas. Indicadores Econômicos FEE. Porto Alegre, v.34, n 01, pp. 89-102, 2006. Disponível em:

$<<$ https://revistas.fee.tche.br/index.php/indicadores/article/view/1446 >> Acesso 05 de março de 2019

PEREIRA, W. E. N. Reestruturação do Setor Industrial e Transformação do Espaço Urbano de Campina Grande - PB a partir dos anos 1990. Tese de doutoramento em Ciências Sociais. CCHLA. UFRN, 2008.

RAIHER, A. P. ; FERRERA DE LIMA, J. ; STADUTO, J. A. R. . As Atividades Produtivas nas Microrregiões Paranaenses: Especialização, Reestruturação e Perfil Locacional. In: IV Encontro Nacional da Associação de Estudos Regionais e Urbanos, 2006, Foz do Iguaçu. Anais o IV ENABER. São Paulo: ABER, v. 1. pp. 130-145. 2006

RESENDE, M., WYLLIE, R. Aglomeração industrial no Brasil: um estudo empírico. Estudos Econômicos (São Paulo), v. 35, n. 3, p. 433-460, 2005. Disponível em: <http://www.revistas.usp.br/ee/issue/view/2934> Acesso em 12 de fevereiro de 2019.

REZENDE, A. C. de ; CAMPOLINA, B. ; PAIXÃO, A. N. Clusterização e localização da indústria de transformação no Brasil entre 1994 e 2009. In: XVIII Fórum Banco do Nordeste de Desenvolvimento e XVII Encontro Regional de Economia, 2012, Fortaleza. Anais do XVII Encontro Regional de Economia, pp. 35-60, 2012.

Disponível em: $<<$ https://www.bnb.gov.br/documents/160445/223813/sim3 mesa1 clusterizacao locali zacao industria transformacao brasil 1994 2009.pdf/ed7a56f7-770d-477c-8a4a9a75f57be8b5>> Acesso em 05 de janeiro de 2019.

SABOIA. J. Desconcentração industrial do Brasil nos anos 90: Um enfoque regional. Pesquisa e planejamento econômico. Vol. 0, n. 1, p. 69-116. Rio de Janeiro. Abr. 2000. Disponível em:<< http://repositorio.ipea.gov.br/bitstream/11058/3413/14/PPE v30 n01 Desconcentrac ao.pdf $>>$ Acesso em 24 de janeiro de 2019.

SABOIA. J. A continuidade do processo de desconcentração regional da indústria brasileira nos anos 2000. Nova Economia. Belo Horizonte. V. 23, n. 02, p.219-278. Maio-agosto. 2013. Disponível em: $<$ https://revistas.face.ufmg.br/index.php/novaeconomia/article/view/2183> Acesso em: 21 de janeiro de 2019. 
SILVA, M. V. B. da. SILVEIRA NETO, R. da M. Dinâmica da concentração da atividade industrial no Brasil entre 1994 e 2004: uma análise a partir de economias de aglomeração e da nova geografia econômica. Econ. Apl. [online]. 2009, vol.13, n.2, pp. 299-331. ISSN 1413-8050. Disponível em: << https://www.revistas.usp.br/ecoa/article/view/1010/1022 >> acesso 15 de fevereiro de 2019.

SOARES, F. A. ; SANTOS, Sandra Maria dos ; Freitas, Elton E. Especialização industrial e economia de escala: uma análise a partir das microrregiões brasileiras. In: XIII Encontro regional de Economia, 2008, Fortaleza. Fórum BNB de desenvolvimento. Fortaleza: BNB, 2008. << https://www.bnb.gov.br/documents/160445/214098/especializacao industria.pdf/cee 6eae3-0aa6-4b8e-b76d-8858451aee80 >> Acesso em 23 de fevereiro de 2019.

VARSANO, R. A guerra fiscal do ICMS: quem ganha e quem perde. In.

Planejamento e Políticas Públicas. Brasília, V. 01, n. 01, p.4-19, jun. de 1997. Disponível em: $<<$ http://repositorio.ipea.gov.br/bitstream/11058/2253/1/td 0500.pdf $>>$ Acesso em 23 de janeiro de 2019. 